\title{
Extending the Regional Analysis Toolkit
}

\begin{abstract}
Greg Landry, Ec.D.
The performance of industries in local communities is affected by a wide range of factors including the emergence of global value chains. Three analytical techniques, along with a classification model, were utilized in this paper to provide better insight into the changes occurring in economic regions across Canada. Based on employment estimates from the 1996 to 2012 period, industries within regions were analyzed using location quotients, traditional shift-share and multi-factor partitioning techniques. The performance of industries within each economic region was also classified in accordance with the Carvalho Classification System. The results revealed that different analytical techniques each provided different views of the change occurring in specific economic regions. While the results are descriptive in nature and should be supplemented with local community input, utilizing a variety of analytical techniques can provide valuable background information when building development strategies. In a new era of global production networks, it is particularly important to have greater insight into the competitive advantages that reside in local communities.
\end{abstract}

Keywords: regional analysis, shift-share, multi-factor partitioning, location quotients, global value chains

\section{Introduction}

The purpose of this paper is to illustrate how various analytical techniques can be combined in order to provide better insight into the changes occurring in the economic landscape of 69 economic regions across Canada. These techniques bring clarity to how shifts in global value chains, division of labour, and the restructuring and outsourcing of business functions (described in further detail below) are shaping local and regional economies. This new landscape of global production networks provides a reason for economic developers to rethink the competitive advantages that reside in their communities and pay closer attention to the underlying changes occurring in the economy.

Changes in economic activity can be thought of as cyclical or structural in nature. Cyclical changes are due to business cycle fluctuations. Structural changes are typically thought of as more permanent shifts in the types of industries that make up an economy and can arise from technical changes such as automation, or from changes in the composition of output due to variations in the types of products people demand. For example, a decline in the demand for newsprint could lead to structurally unemployed workers in the newsprint industry. 
Structural shifts in local economies are also affected more than ever by another phenomenon. The global economy is increasingly structured around global value chains that account for a rising share of international trade, GDP and employment (Gereffi and Fernandez-Stark, 2011). A value chain refers to the full range of activities that firms and workers do to bring a product from conception to its end use. This can include activities such as research and development, design, production, marketing, distribution and support to the final consumer. A global value chain exists when these activities are performed in integrated international production networks. While the division of labour in economic production was observed in ancient civilizations where the distinct assignment of jobs in different cities coincided with an increase in trade and economic interdependence (Kriwaczek, 2012), over the past two decades the international fragmentation of production has rapidly increased due to changes in the business strategies, new technologies, and the systematic liberalisation of trade and investment (OECD, WTO, UNCTAD, 2013). The whole process of producing goods, from raw materials to finished products, is increasingly global in scope with each activity in the chain carried out wherever the necessary skills and materials are available at competitive cost and quality.

The outsourcing of individual business functions is a strategy companies now often use to cut costs, become more efficient, expand, and gain access to new markets. Offshoring involves the relocation by a company of a business process or function from one country to another. While "offshoring" from North American countries to low cost developing countries was once thought to affect only manufacturing jobs, in the early 2000s, other industries were also affected, in particular, information technology and related areas. In an attempt to shed more light on how workplaces and industries were changing, the Mass Layoff Statistics (MLS) program administered by the United States Department of Labour was revamped in 2007 to also collect the business functions and processes affected by layoffs. The program soon revealed that offshoring job losses were not just confined to sectors such as manufacturing and information technology, but were also largely occurring in specific business functions such as those performed by information technology workers in almost any sector of the economy (Brown, 2008).

In an era with highly integrated global networks, where different elements of the production process are spread across the globe, the economic structure of many local economies will be highly impacted. In this paper, several analytical tools are utilized to shed light on the changing landscape of economic activity across Canada's economic regions. The following section describes these tools in detail and provides the methodology for the analysis. The next section describes the results of the analysis, and finally some overall conclusions are offered. 


\section{Methodology}

Three analytical techniques, along with a classification model, were utilized. The first analytical technique that is used is referred to as shift-share analysis. By comparing the change of an economic variable, such as employment in a community or region to a reference area such as a nation, the analyst utilizing this tool can decompose the change in the variable over two periods into different components of growth or decline. The traditional form of shift-share analysis decomposes the change into three components. Although the calculations are typically the same, analysts will often use different labels for the three effects.

The second analytical technique utilized in this paper is a multi-factor partitioning (MFP) version of the standard shift-share approach. A major difference is that in MFP shift-share, the change in the total growth in a region and a reference area is decomposed into four components.

The third technique used is location quotient analysis. Location quotients are used to compare a region's share of economic activity in a particular industry to the national or reference area share of economic activity in the same industry. The result reveals the degree of regional specialization in each industry. If the location quotient for a particular industry is between zero and one, the region is less specialized than the reference area; conversely, location quotients greater than one reveal higher specialization of the industry in the local economy than in the reference area's economy.

Finally, the Carvalho Classification System is also used. It combines the outputs of location quotient and shift-share analysis. Each technique is later explained in further detail.

The data utilized in the computations was obtained from Statistics Canada's CANSIM Table 282-0061. The data in this table is drawn from the Labour Force Survey (LFS) and provides employment estimates according to the North American Classification System (NAICS) for 69 economic regions. The national average was used as the reference area. The period from 1996 to 2012 was chosen due to data availability and consistency across economic regions, as the boundaries for economic regions were different prior to 1996. Furthermore, LFS estimates from 1987 to 1995 are based on the 2001 census population counts and estimates from 1996 onwards are based on 2006 census population counts.

While the LFS provides estimates for 16 industries, for the purposes of this paper three goodproducing industries were aggregated into a category labelled the "Resource and Energy Sector" and five service-producing industries were aggregated into a category labelled the "KnowledgeBased Services Sector"1 This was necessary in order to obtain a full set of data for all economic

\footnotetext{
${ }^{1}$ The "Resource and Energy Sector" includes: Agriculture; Forestry, Fishing, Mining, Quarrying, Oil and Gas; and Utilities. The "Knowledge-Based Services Sector" includes: Finance, Insurance, Real Estate and Leasing;
} 
regions, as employment estimates for many of the smaller industry categories were suppressed in a number of regions due to small sample size.

\section{Traditional Shift-Share}

The traditional shift-share approach decomposes the actual change in the regional employment of an industry into three components: a reference area growth effect, an industrial mix effect, and a differential shift effect.

Where $X$ represents a variable such as employment, ${ }_{i}$ represents an industry, ${ }_{j}$ represents a region, and ${ }^{t}$ represents time, a temporal change between ${ }^{t}$ and ${ }^{t+n}$ can also be written as follows:

$X_{i j}^{t+n}-X_{i j}^{t}=R G_{i j}^{t+n}+I M_{i j}^{t+n}+D S_{i j}^{t+n}$

Each of the three components of change can be further expressed as follows:

$R G_{i j}=X_{i j} \times g_{n}$

$I M_{i j}=X_{i j} \times\left(g_{i n}-g_{n}\right)$

$D S_{i j}=X_{i j} \times\left(g_{i j}-g_{i n}\right)$

Where

$g=$ the growth of variable $X$ over the time period (between ${ }^{t}$ and ${ }^{t+n}$ );

$g_{n}=$ the reference area $(\%)$ growth of variable $X$ during this period;

$g_{i n}=$ the reference area $(\%)$ growth by industry $_{i}$ of variable $X$ during this period; and

$g_{i j}=$ the regional (\%) growth by industry ${ }_{i}$ of variable $X$ during this period;

$X_{i j}^{t+n}-X_{i j}^{t} \quad$ represents the actual change in local industry employment observed for

the time periods under consideration.

$R G_{i j} \quad$ represents the reference area growth effect. This component, sometimes referred to as the national share, is the change that would occur if all of the region's industries grew at the same rate as growth in employment in a reference area such as a national growth rate.

$I M_{i j} \quad$ represents the industrial mix effect. This component is the change that would occur if the region's industries grew at the same rate as a reference area's industries.

Professional, Scientific and Technical Services; Business, Building and Other Support Services; Information, Culture and Recreation; and Public Administration. 
$D S_{i j} \quad$ represents the differential shift effect. This component, sometimes referred to as the regional shift effect, is the difference between actual change and the sum of the reference area growth effect and industrial mix effect. This residual is intended to capture regional specific factors in relative growth or decline. This is the most important piece because it shows whether the local industry is growing more quickly than the reference area or if it is losing share.

\section{Multi-factor Partitioning}

Srinath and Ray (1990) have developed a Multi-Factor Partitioning (MFP) version of the standard shift-share approach, where the difference between the total growth in the region and national growth is decomposed into four components. It can be written as follows:

$X_{j}^{t}\left(g_{j}-g_{n}\right)=\sum_{i} X_{i j}^{t}\left(\hat{g}_{j}-\hat{g}_{n}\right)+\sum_{i} X_{i j}^{t}\left(\hat{g}_{i n}-\hat{g}_{n}\right)+\sum_{i} X_{i j}^{t}\left(g_{i j}-\hat{g}_{i n}-\hat{g}_{j}+\hat{g}_{n}\right)+\sum_{i} X_{i j}^{t}\left(\hat{g}_{n}-g_{n}\right)$

Where

$X_{j}^{t}\left(g_{j}-g_{n}\right)$ represents the difference between growth in the region and the reference area growth

$\sum_{i} X_{i j}^{t}\left(\hat{g}_{j}-\widehat{g}_{n}\right)$

represents the regional effect

$\sum_{i} X_{i j}^{t}\left(\hat{g}_{i n}-\hat{g}_{n}\right)$

represents the industrial mix effect

$\sum_{i} X_{i j}^{t}\left(g_{i j}-\hat{g}_{i n}-\hat{g}_{j}+\hat{g}_{n}\right)$

represents the net effect of all interactions for each region (the interaction effect)

$\sum_{i} X_{i j}^{t}\left(\hat{g}_{n}-g_{n}\right)$ represents the difference between the standardized and crude reference area growth rates (the allocation effect)

The "crude" regional growth rates $g_{j}$ and reference area growth rate $g_{n}$ are derived as follows: $g_{j}=\sum_{i} g_{i j} \frac{X_{i j}^{t}}{X_{j}^{t}} \quad$ and $\quad g_{n}=\sum_{j} g_{j} \frac{X_{j}^{t}}{X_{n}^{t}}$

The "standardized" regional growth rate $\hat{g}_{j}$ and growth rate for each industry $\hat{g}_{i n}$ are derived as follows:

$\hat{g}_{j}=\sum_{i} g_{i j} \frac{X_{i n}^{t}}{X_{n}^{t}} \quad$ and $\quad \hat{g}_{i n}=\sum_{j} g_{i j} \frac{X_{j}^{t}}{X_{n}^{t}}$ 
The "standardized" reference area growth rate $\hat{g}_{n}$ can be calculated as follows:

$\hat{g}_{n}=\sum_{i} \hat{g}_{i n} \frac{X_{i n}^{t}}{X_{n}^{t}}=\sum_{j} \hat{g}_{j} \frac{X_{j}^{t}}{X_{n}^{t}}$

\section{Location Quotient Analysis}

Location Quotients (LQs) are ratios that allow an area's concentration of employment by industry to be compared to a reference area's concentration of employment and can be calculated as follows:

$L Q=\frac{\frac{X_{i j}}{X_{j}}}{\frac{X_{i r}}{X_{r}}}$

Where:

$X_{i j}$ represents total employment in industry $i$ in region $j$.

$X_{j}$ represents total employment in region $j$.

$X_{i r}$ represents total employment in industry $i$ in reference area $r$.

$X_{r}$ represents total employment in reference area $r$.

The location quotient provides a measure of the relative regional concentration of an industry. A location quotient for an industry that produces a result equal to one indicates that the industry's share of total local employment matches the same industry's share of total employment in the reference area. This implies that the industry's contribution to the local economy matches the same industry's contribution to the economy of the reference area.

A result greater than one, indicates that the industry's share of total local employment exceeds the same industry's share of total employment in the reference area. This suggests that the industry's contribution to the local economy surpasses the same industry's contribution to the economy of the reference area (in other words, the local economy specializes in that industry).

On the other hand, if the calculation of the location quotient for an industry produces a result of less than one, this implies that the industry's share of total local employment is less than the same industry's share of total employment in the reference area. The implication in this case is that the industry's contribution to the local economy lags the same industry's contribution to the economy of the reference area. 


\section{Carvalho Classification System}

The Carvalho Classification System provides a method of categorizing industries into one of 12 descriptive classifications based on three indicators: the location quotient, the industrial effect and the differential shift effect. As listed in table 1, the descriptive categories range from "driving" to "marginal".

Table 1 - Carvalho Classification System

\begin{tabular}{|l|l|l|l|}
\hline & Location Quotient & Industrial Mix Effect & Differential Shift Effect \\
\hline Driving & $>1.25$ & positive & positive \\
\hline Accelerating & $0.75-1.25$ & positive & positive \\
\hline Rising & $<0.75$ & positive & positive \\
\hline Evolving & $>1.25$ & negative & positive \\
\hline Transitional & $0.75-1.25$ & negative & positive \\
\hline Moderate & $<0.75$ & negative & positive \\
\hline Promising & $>1.25$ & positive & negative \\
\hline Yielding & $0.75-1.25$ & positive & negative \\
\hline Modest & $<0.75$ & positive & negative \\
\hline Challenging & $>1.25$ & negative & negative \\
\hline Vulnerable & $0.75-1.25$ & negative & negative \\
\hline Marginal & $<0.75$ & negative & negative \\
\hline
\end{tabular}

\section{Results}

Shift-share, multi-factor partitioning, and location quotient analysis were performed for 69 economic regions and ten industry sectors for the 1996 to 2012 period. In the vast majority of cases, the direction of change of the industrial mix effect - the change that would occur if the region's industries grew at the same rate as a reference area's industries - remained the same for both shift-share analysis and multi-factor partitioning. However, in particular industries within regions, the extent of employment change that can be attributed to the industrial mix effect is typically smaller when using multi-factor partitioning. This is due to the fact that part of the industrial mix effect in multi-factor partitioning is captured under another component.

The main difference between shift-share and multi-factor partitioning is the change in the remaining components. Looking at the "Resource and Energy Sector" for example, 25 out of 69 regions had a positive differential shift effect based on shift-share analysis. This effect is intended as an indicator of whether a region has a local competitive advantage in a particular industry relative to the reference area. When looking at the results of multi-factor partitioning, 31 out of 69 regions had a positive interaction effect. According to Ray, Lamarche and Biffignandi (2011), multi-factor partitioning accounts for the fact that industries are not 
distributed proportionately among the regions. For instance, a greater concentration of various types of industries can often be found in metropolitan regions. The growth performance of individual industries is also sensitive to the specific locational advantages of each region. These specific region-industry differences in growth rates are extracted and measured separately as interaction effects.

While in some cases shift-share and multi-factor partitioning do produce similar results, in other cases the results can be quite different. For instance, Calgary, Edmonton and Wood BuffaloCold Lake, Alberta respectively experienced the highest positive differential shift effect and the largest positive interaction effect for the Resource and Energy Sector. On the other hand, while Red Deer, Alberta had a positive differential shift effect, it also had one of the declines in terms of an interaction effect.

Map 1a shows the performance of the Resource and Energy Sector between 1996 and 2012 by economic region according to the Carvalho Classification System. The sector in many regions is classified as "challenging" due to a high location quotient along with negative industrial mix and differential shift effects. The sector is classified as "evolving" in what appears to be regions with a high concentration of employment in industries related to oil and gas. All regions of the country experienced a negative industrial effect as a result of the national decline in employment in the lion's share of resource-based industries. Map 1b shows the interaction effect component of employment change in the Resource and Energy Sector by economic region between 1996 and 2012. The interaction effect is divided into four categories: strongly positive, representing an increase in employment of more than 2,000; positive, representing an increase in employment of between 0 and 2,000; negative, representing an decrease in employment of between 0 and 2,000; and strongly negative, representing a decrease in employment of more than 2,000. Comparing Map 1a with Map 1b, one can view that in regions where the sector's performance is classified as "evolving" the sector is also typically classified as having a strongly positive interaction effect.

Map 2a shows the performance of the Manufacturing Sector by economic region according to the Carvalho Classification System. There are seven economic regions that are classified as "challenging". Interestingly, comparing Map 2a with Map 2b reveals that all regions with "challenging" manufacturing sectors have a positive interaction effect with the exception of the Hamilton-Niagara Peninsula Region in Ontario. This may illustrate a key difference in the results that can be achieved by using both shift-share and multifactor partitioning. While Map 2a draws attention to a number of regions that are dependent on the declining pulp and paper industry, Map 2b draws attention to the decline in the more diversified manufacturing sector in Southern Ontario.

Unlike the resource and manufacturing sectors, the Knowledge-Based Service Sector has a very positive industrial mix effect in all regions. Based on shift-share analysis, it is estimated to 
account for close to 90,000 of the 410,000 jobs added to Toronto's knowledge-based services between 1996 and 2012. Map 3a illustrates the sector is classified as "driving" in Toronto, Ottawa, and the Outaouais and Capitale-Nationale regions of Quebec. Toronto, Calgary, Ottawa, and Kitchener-Waterloo-Barrie have the highest positive differential shift effects. Toronto, Montréal and Ottawa have the highest positive interaction effects.

For some economic regions, both traditional shift-share and the multi-factor partitioning version of shift-share analysis yielded similar results for the Knowledge-Based Service Sector. The Moncton-Richibucto Economic Region of New Brunswick (which experienced a large increase in employment in the customer contact and support business function) has almost identical differential shift effect and interaction effects. While Vancouver Island and Coast, British Columbia has a negative differential shift effect, it has a positive interaction effect. On the other hand, Calgary has a positive differential shift effect but negative interaction effect.

Between 1996 and 2012, employment growth in the Knowledge-Based Service Sector grew faster than the national average in the Moncton-Richibucto Economic Region. The sector also accounted for close to half of the employment growth in the region. In the Vancouver Island and Coast Economic Region, the sector did not grow as fast as the national average, but still accounted for a large portion of the region's total employment growth during that period. In the Calgary Economic Region, employment growth in the sector outpaced the national average but only accounted for about a quarter of the region's employment growth.

\section{Map 1a - Resource and Energy Sector by Carvalho Classification}

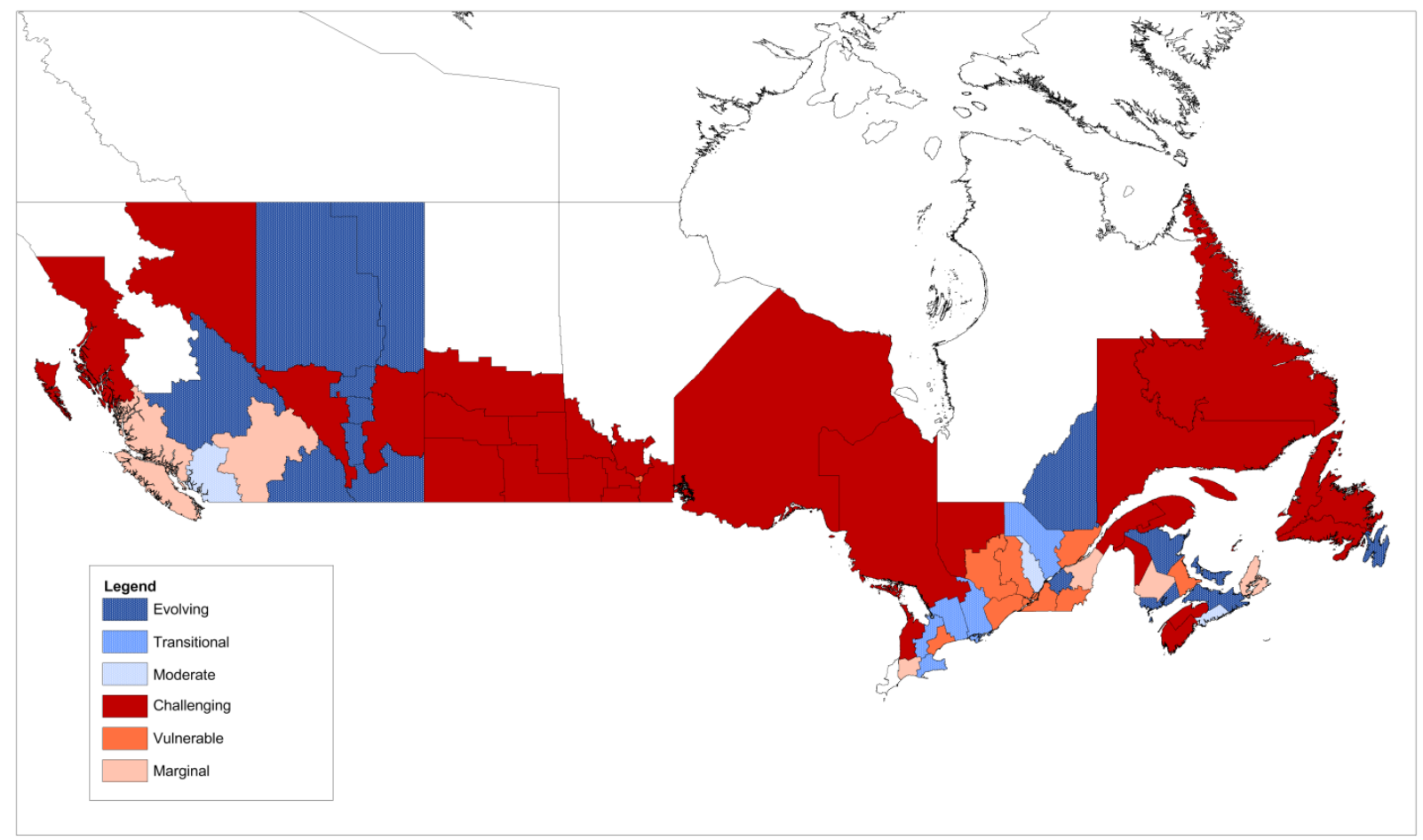


Map 1b - Resource and Energy Sector by Multi-Factor Partitioning Interaction Effect

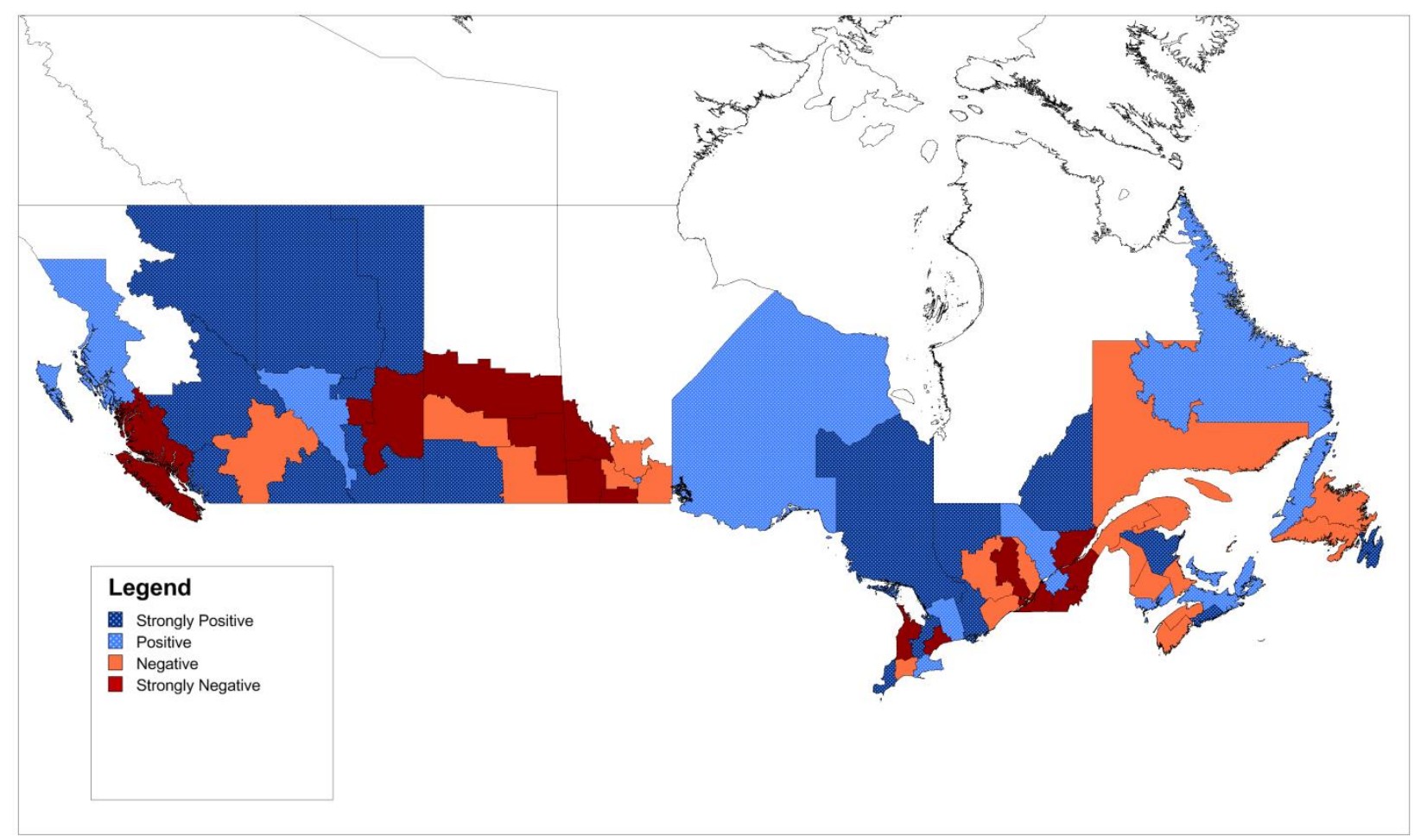

Map 2a - Manufacturing Sector by Carvalho Classification

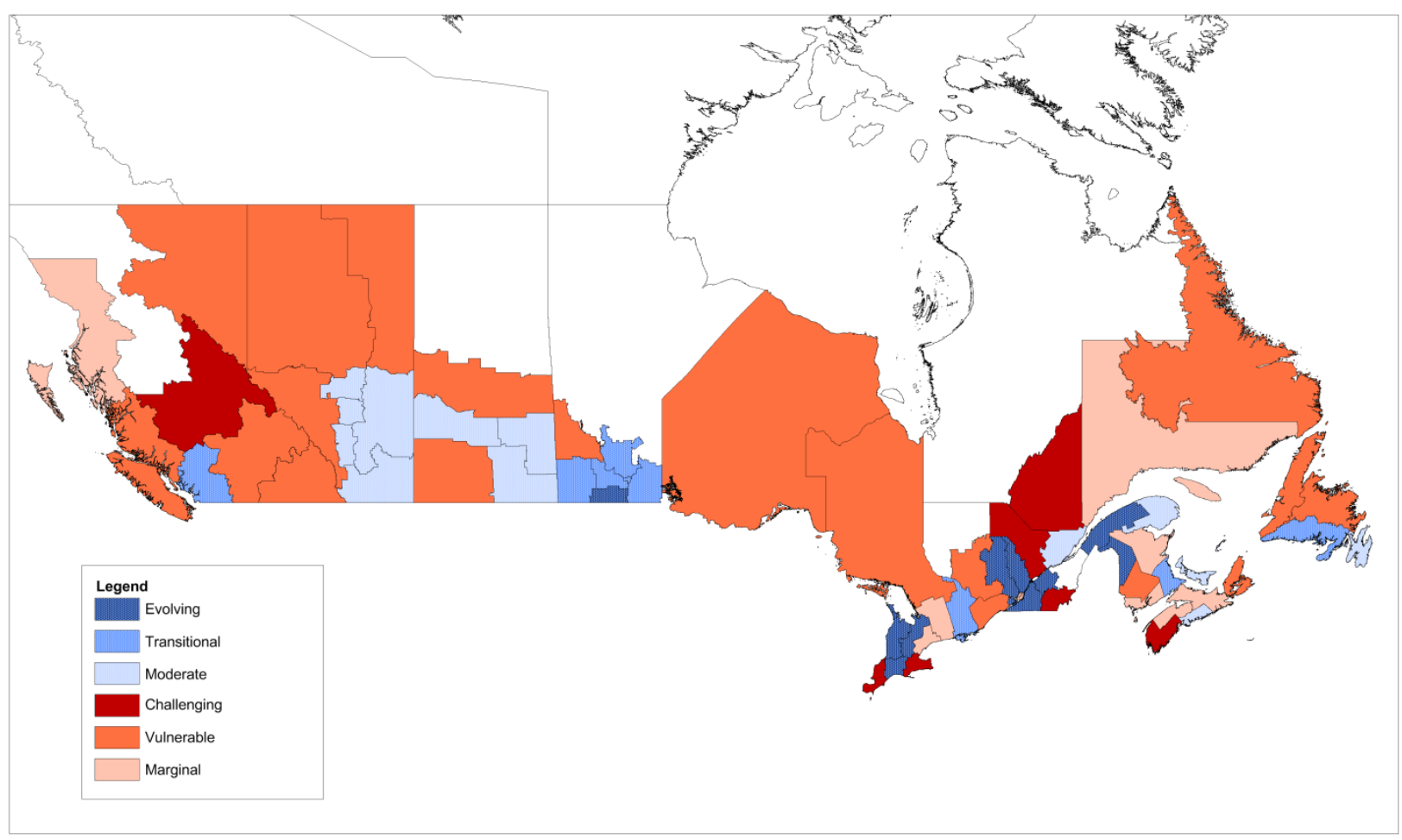


Map 2b - Manufacturing Sector by Multi-Factor Partitioning Interaction Effect

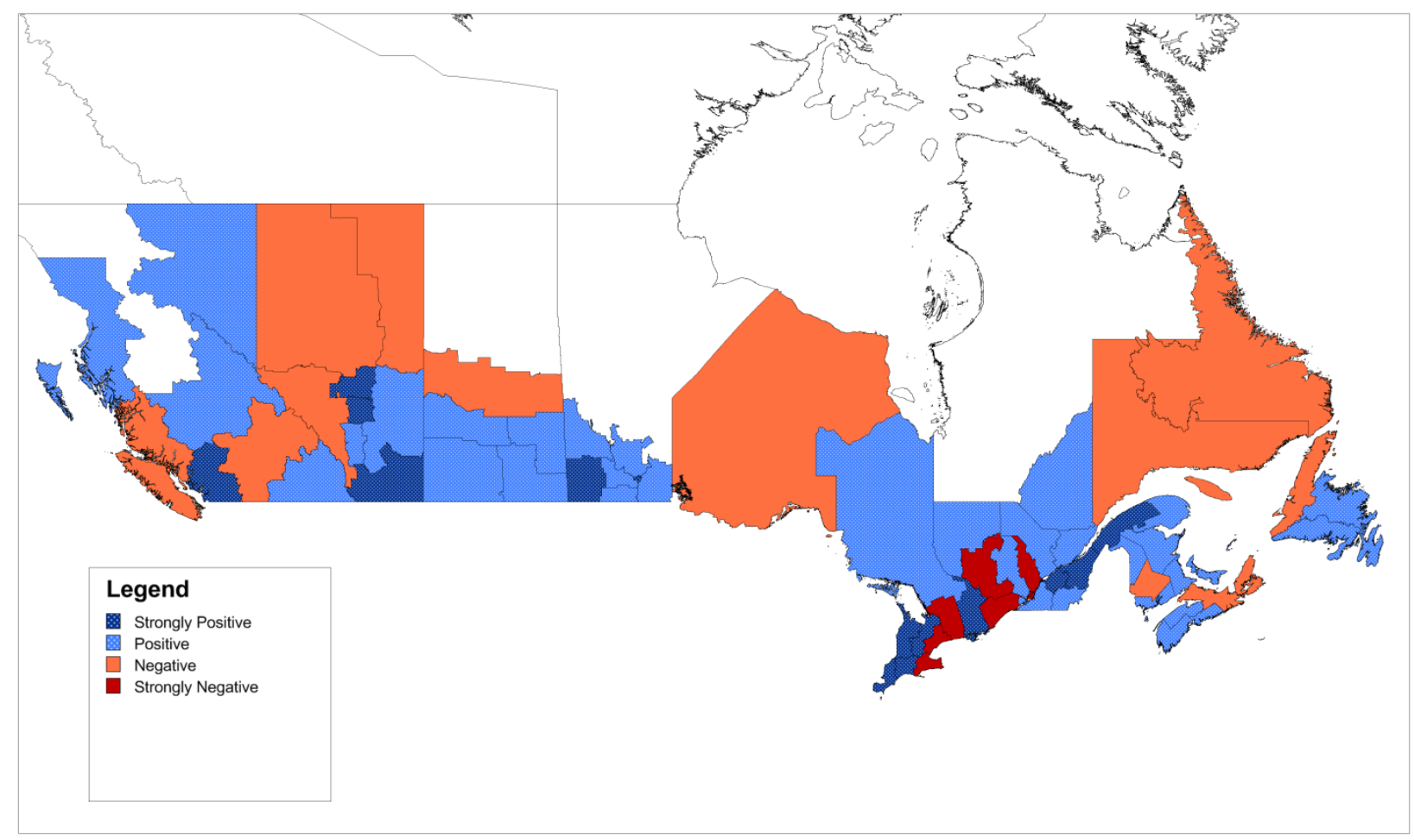

Map 3a - Knowledge-Based Service Sector by Carvalho Classification

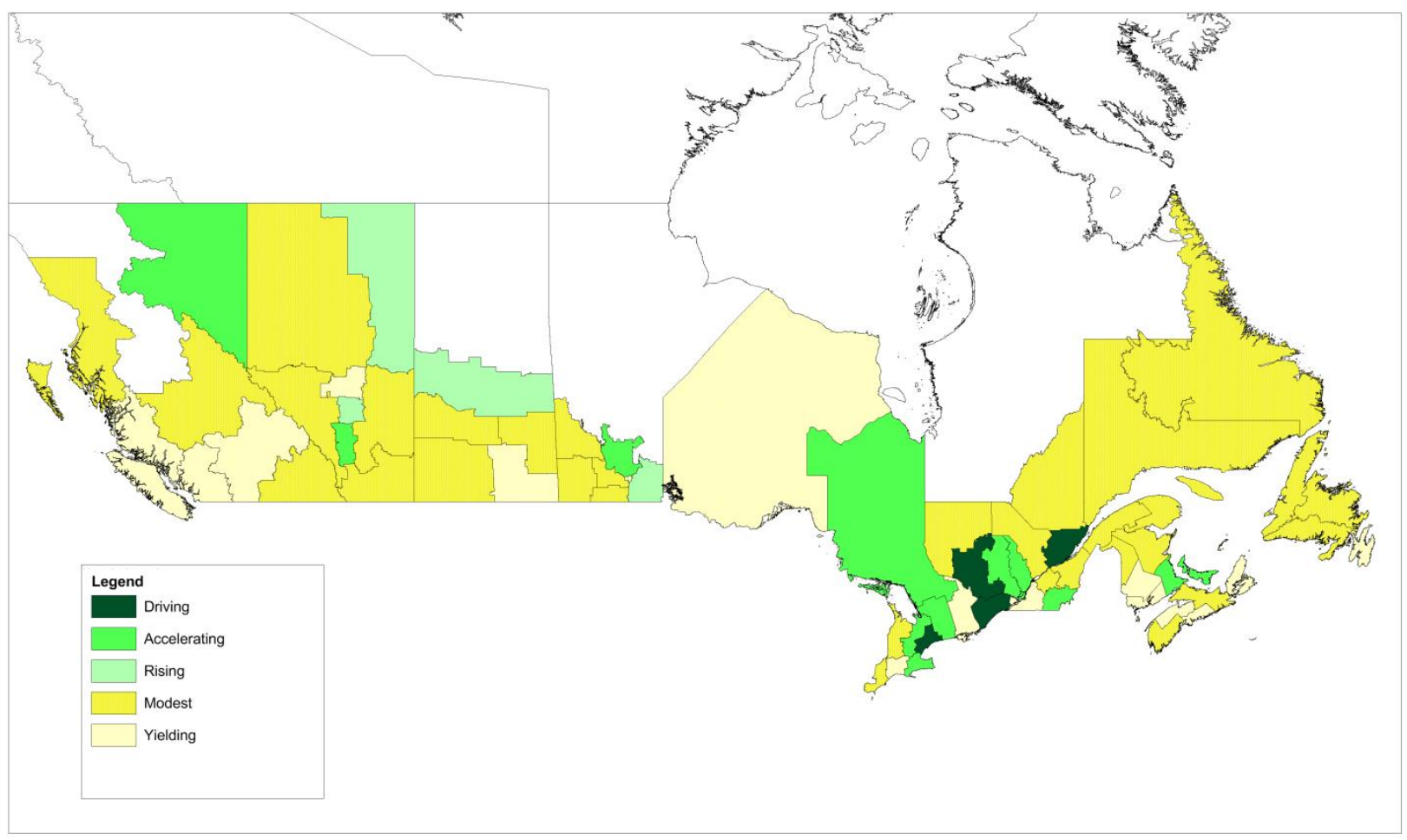


Map 3b - Knowledge-Based Service Sector by Multi-Factor Partitioning Interaction Effect

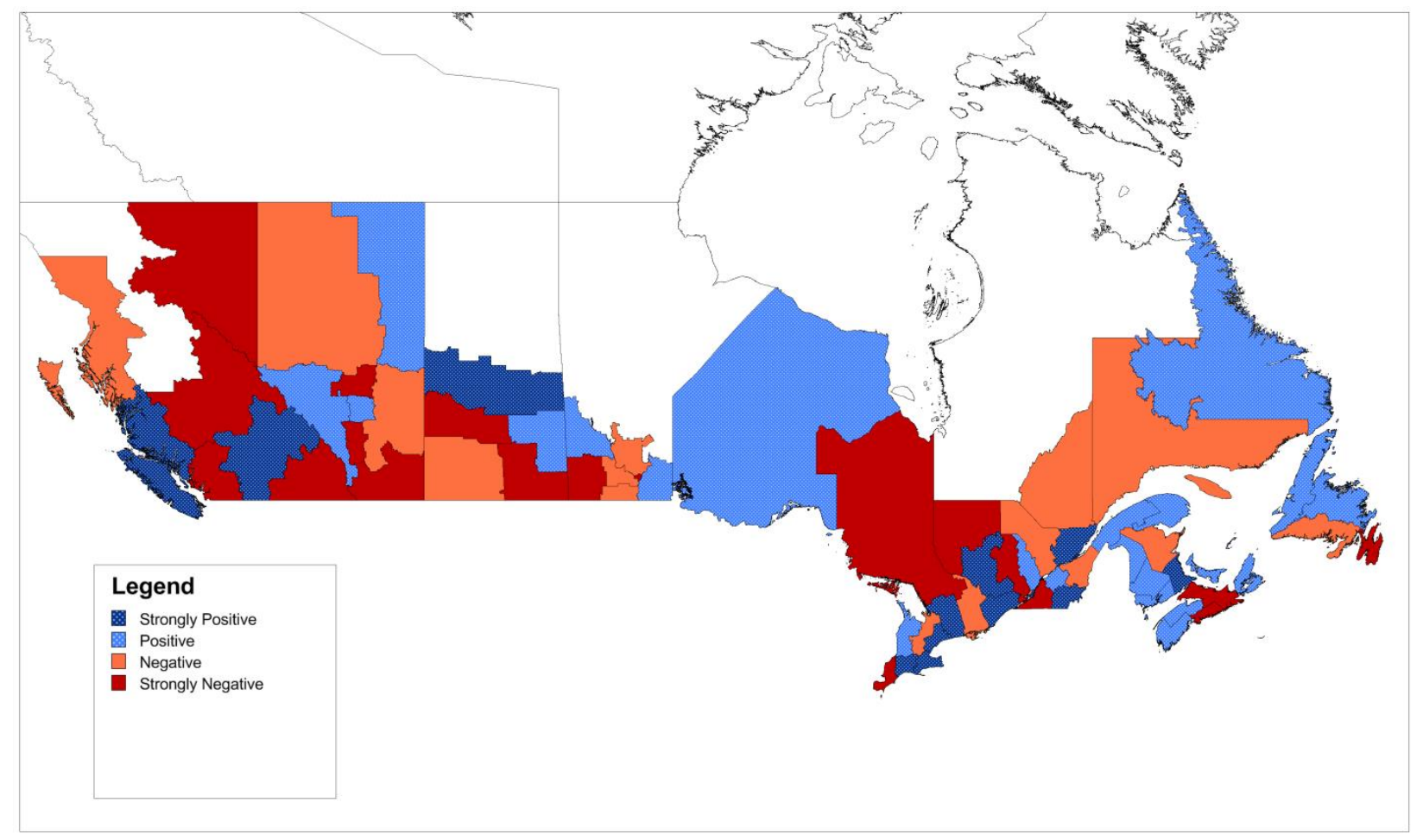

\section{Conclusion}

This paper utilized three analytical techniques along with a classification model to shed light on the changing landscape of economic activity across Canada's economic regions. The different analytical techniques each provided different views of the change occurring in local economies.

The traditional and multi-factor partitioning versions of shift-share analysis can provide substantially different information in terms of understanding employment growth and decline in particular industries. Traditional shift-share analysis typically attributes a larger share of growth of an industry in a particular region to the industrial mix effect. Multi-factor partitioning can enhance our understanding of regional growth rates in particular industries as the methodology partitions these rates into finer components than produced by the traditional shift-share methodology. Isolating and measuring the interaction effect can provide further insight into industrial changes occurring in economic regions and other local economies. Aside from reference area growth and industrial mix effects, the performance of a local industry could also be related to whether it is located in a regional economy dominated by growing industries versus a regional economy dominated by declining industries. While traditional shift-share analysis may still reveal unique regional advantages in particular industries that ought to be identified and fostered; multi-factor partitioning can provide additional information by taking into account the 
fact that the performance of particular industries in a region may be interwoven with the performance and concentration of other industries in the same region.

Utilizing analytical tools that show an array of industries in a particular region are simultaneously outperforming or underperforming the same industries in a reference area may point to shifts in industries linked together through local supply chains or the movement of business functions in global value chains. Techniques like location quotient and different forms of shift-share analysis are descriptive in nature and do not explain the underlying sources of why an industry is more concentrated or undergoing a relatively larger transformation in a particular region. Therefore, economic development professionals should also supplement findings from these techniques with local input when building regional development strategies. Through extending their analytical toolboxes, however, more information can be brought into the planning process which can provide further clarity in efforts to identify local competitive advantages in this era of global change.

\section{Author Biography}

Greg Landry is the Director of the Sector Development Division within the Nova Scotia Department of Economic and Rural Development and Tourism. He has worked in both land use planning and economic development for various levels of government. He holds a Masters of Development Economics and a Masters of Urban and Rural Planning from Dalhousie University.

\section{References}

Brown, S.P. (2008). Business Processes and Business Functions: A new way of looking at employment. Monthly Labor Review, December, 51-70.

Gereffi, G. \& Fernandez-Stark, K. (2011). Global Value Chain Analysis: A Primer. Center on Globalization, Governance, Competitiveness (CGGC), Duke University.

Kriwaczek, P. (2012). Babylon: Mesopotamia and the birth of civilization (1st U.S. ed.). New York, NY: Thomas Dunne Books/St. Martin's Press.

OECD, WTO, UNCTAD. (2013). Implications of Global Value Chains for Trade, Investment, Development and Jobs. Prepared for the G-20 Leaders Summit. Saint Petersburg, RU Federation).

Ray, D.M., Lamarche, R.H. \& Biffignandi, S. (2011). The Geography of Employment Growth in Western Canada: A Regional Typology based on Multifactor Partitioning. Canadian Association of Geographers Annual Meeting and Conference.Calgary, AB. 
Srinath, K.P. \& Ray D.M (1990). Use of Standardization in the Analysis of Rates. Proceedings of the American Statistical Association Conference. Los Angeles, CA 